\title{
Deep sublevel cave mining and surface influence
}

\author{
J Sjöberg Itasca Consultants $A B$, Sweden \\ F Perman Itasca Consultants $A B$, Sweden \\ D Lope Álvarez Itasca Consultants $A B$, Sweden \\ B-M Stöckel Luossavaara-Kiirunavaara Aktiebolag (LKAB), Sweden \\ K Mäkitaavola Luossavaara-Kiirunavaara Aktiebolag (LKAB), Sweden \\ E Storvall $\AA$ F Infrastructure, Sweden (formerly Itasca Consultants $A B$, Sweden) \\ T Lavoie Itasca Consulting Group Inc., USA
}

\begin{abstract}
With increasing mining depths and excavation volumes comes not only increased rock stresses and more difficult underground mining conditions, but also increased surface effects, in particular from cave mining. The surface effects of deep sublevel cave mining are not well understood and are further explored in this paper, through a case study of the LKAB Kiirunavaara Mine. Two different numerical modelling approaches were used to quantify potential surface effects. The first approach was applied to Sjömalmen (Lake Orebody). This is a non-daylighting portion in the northern end of the mineralisation, above which surface cratering has developed. Three-dimensional (3D) numerical modelling, using the Itasca caving algorithm, was applied to study future mining of Sjömalmen down to Level $1365 \mathrm{~m}$. In the second approach, 2D modelling of the main portion of the Kiirunavaara orebody was conducted, using a caving simulation scheme initially developed at the Lulea University of Technology. This model enabled simulating caving to large depths, in this particular case down to Level $1800 \mathrm{~m}$, for prediction on hangingwall deformations. The actual caving is simulated implicitly in these continuum models. Observational data on cave development and surface cratering, as well as measured ground surface deformations, were used to calibrate the numerical models. For both approaches, deeper mining was shown to significantly affect the ground surface. Ground deformations are not arrested by bulking and/or increased confinement as mining goes deeper. Both modelling approaches have distinct pros and cons. The 2D approach is only applicable to the main portion of the orebody, where 2D geometrical conditions can be reasonably assumed, but calculation times are faster compared to the 3D approach. The models were fairly sensitive to the geomechanical properties and choice of constitutive model. This facilitated calibration, but also implies that an improved characterisation of the rock mass in the cap rock and hangingwall is important for increased reliability in predictive analyses.
\end{abstract}

Keywords: deep mass mining, ground deformations, numerical modelling, prediction

\section{Introduction and problem description}

\subsection{Background}

Cave mining is becoming an increasingly attractive mining method for massive, large-scale orebodies, due to its cost-efficiency and possibility of high degrees of mechanisation and automation. This trend also pertains to deposits at larger depths. Increasing mining depths and extraction volumes are often associated with an increase in rock stress and more difficult mining conditions. However, deeper cave mining may also result in more pronounced effects on the ground surface. In all cave mining, caving of the surrounding rock is an integral pre-requisite that, however, also results in caving and fracturing of the host rock and, eventually, mining-induced ground deformations. These phenomena occur primarily on the hangingwall 
side of an orebody, but to some extent also on the footwall side. With cave mining starting near the ground surface, or below an open pit, ground surface effects develop more-or-less immediately. Comparatively less is known about the influence on the ground surface from deep cave mining. Are we likely to experience the same type of mechanisms and ground disturbance with increasing depth? Or will deep to ultra-deep cave mining lead to less surface effects due to confinement, bulking effects, or changes in mechanisms? These issues are further explored in this paper, through a case study of the Luossavaara-Kiirunavaara Aktiebolag (LKAB) Kiirunavaara Mine in Sweden.

\subsection{Kiirunavaara case study}

Iron ore has been extracted from the Kiirunavaara Mine for more than 100 years, initially from open pit mining, but since the early 1960 s through underground sublevel cave mining. The mineralisation extends for a length of more than $4 \mathrm{~km}$, striking nearly north-south, and dipping 55-60 towards east (Figure 1). The northern portion of the orebody (named Sjömalmen) is non-daylighting and lies beneath a now-drained lake, with the mineralisation plunging north (Figure 2).

The mine is owned and operated by the LKAB mining company. Annual production is around 28 million metric tons of crude iron ore, making it one of the largest underground metal mines in the world. The deepest active production is currently at Level $1051 \mathrm{~m}$, which translates to around $820 \mathrm{~m}$ below the ground surface. The main haulage level is at Level $1365 \mathrm{~m}$. While current mining plans only extend to Level $1365 \mathrm{~m}$, the mineralisation is open at depth and may potentially be mined at significantly larger depths in the future.

The sublevel cave mining at Kiirunavaara has resulted in extensive fracturing and associated ground surface deformations on the hangingwall side. The municipality of Kiruna is located in close proximity to the mine, and primarily on the hangingwall side. In the long-term perspective, it is not possible to have any residential buildings or infrastructure within the fracture zone and cave zone resulting from mining.

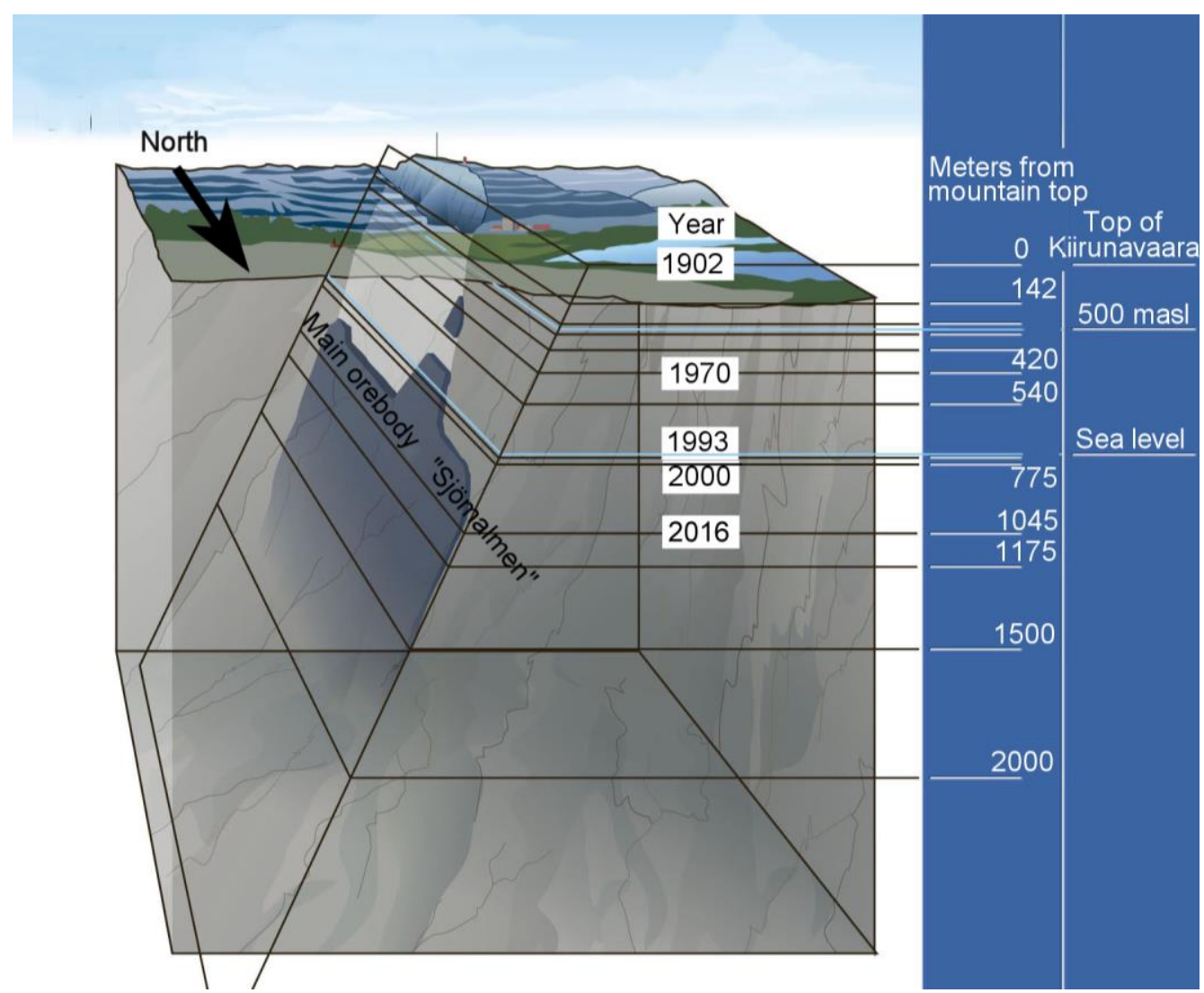

Figure 1 Perspective view showing the Kiirunavaara Mine, mining levels and approximate year of mine extraction for selected levels 


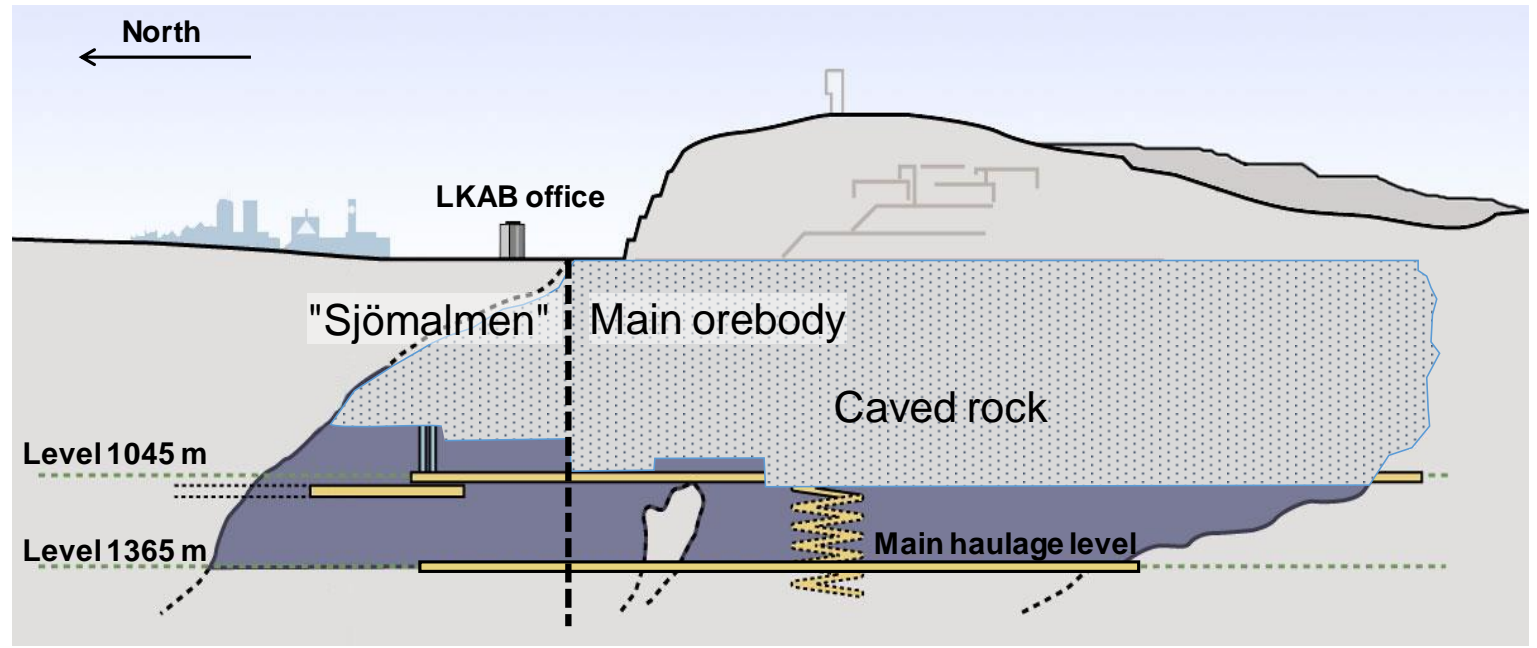

Figure 2 Long section of the Kiirunavaara orebody, looking (east) towards the hangingwall with current mining levels (caved rock) marked

On the hangingwall side, fracturing and deformations have been developing more-or-less continuously since the start of underground mining, but the situation has been exacerbated during the last decade as the mining-induced ground deformations have progressed farther east toward larger portions of the city. Mining of Sjömalmen has further increased the complexity, with surface cave cratering emerging some three years after the start of mining through caving of the cap rock. The surface crater has enlarged toward north, along with an increase in measurable ground deformations on the ground surface, as illustrated in Figure 3.
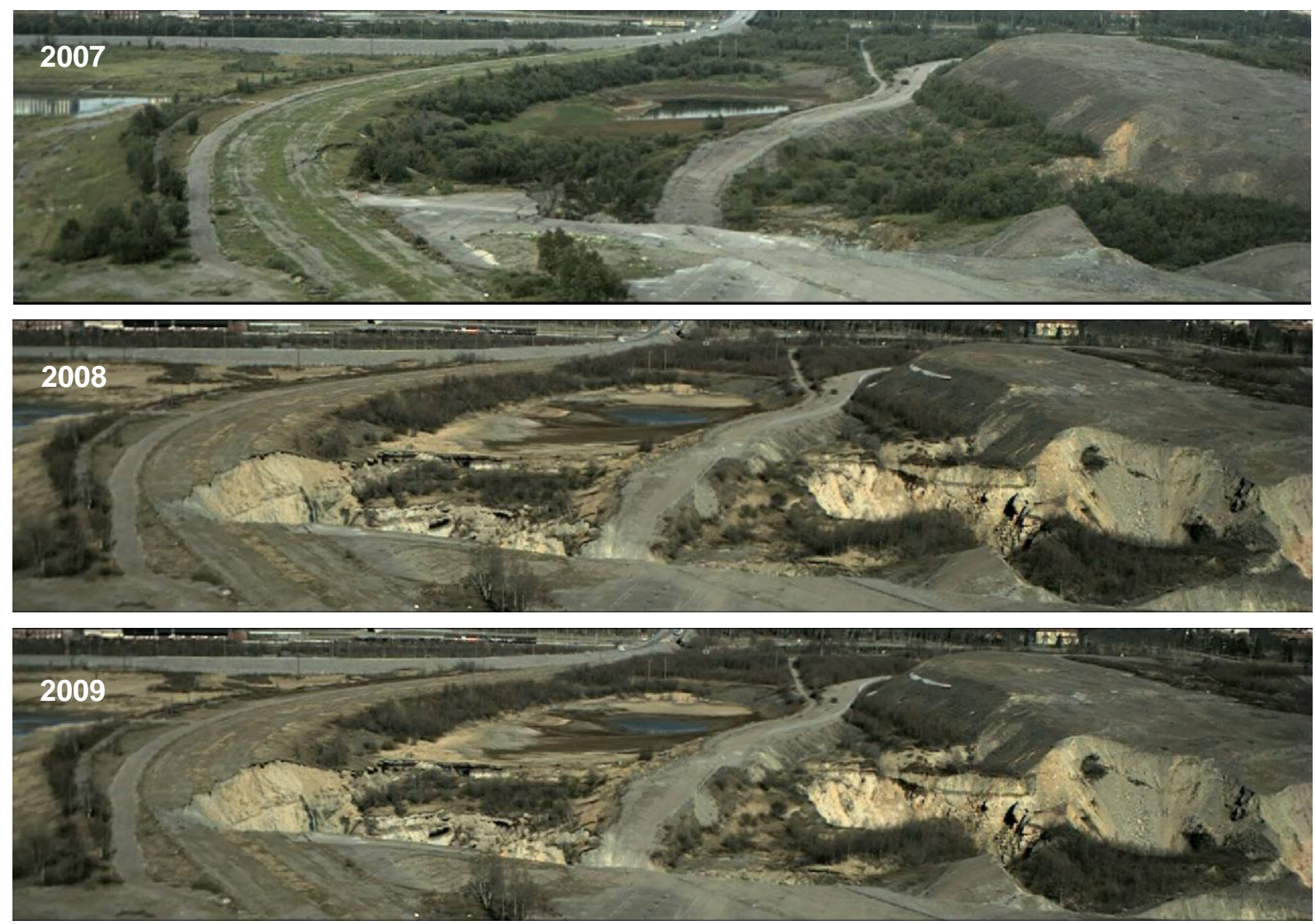

Figure 3 Aerial view, looking (east) towards the hangingwall, showing surface cratering and fracturing above the Sjömalmen portion of the orebody from 2007 to 2009 
A process of 'urban transformation' is now in place in which the city of Kiruna is progressively relocated to a new area, undisturbed from mining activities. Monitoring of ground deformations is conducted on a regular basis to aid in the urban transformation process. GPS-monitoring is currently used for this purpose, with a measurement network of nearly 400 hubs in place. Readings are taken up to four times per year, and the results are evaluated primarily against an 'environmental criterion' for allowable mining-induced ground deformations in Kiruna, regulated through a ruling in the Environmental Court in Sweden. The environmental criterion states that the ground outside the mining industrial area cannot be affected by more than $0.3 \%$ strain (horizontally) and $0.2 \%$ tilt (vertically). These limits are based on investigated sensitivity of critical infrastructure. More recently, a project on the application of InSAR for monitoring ground deformation has been conducted at Kiruna (Mäkitaavola et al. 2016). InSAR technology may be considered as a complement to GPS-monitoring in the future.

While essential to being able to uphold regulatory criteria and understand ground behaviour, all monitoring activities are reactive rather than proactive. For future mining - and in particular for very deep sublevel cave mining - some means of predicting the overall surface effects is required. It is anticipated that fracturing and mining-induced deformations will continue to develop but uncertainties, for example the possible confining effects with deep mining, exists. Moreover, it has been hypothesised that mining under the increasingly thicker cap rock in the Sjömalmen area results in less surface effects in the future. Currently, predictions of future ground deformations are based on empirically derived limit angles (Stöckel et al. 2013). Although this methodology has proven to work satisfactorily so far, it suffers from the inherent uncertainty associated with all empirical approaches in that they are only valid within the data range upon which they were developed. Thus, for mining at significantly larger depths and/or under conditions not previously encountered, the existing prognosis methodology may not be applicable.

\subsection{Approach}

In the current work, two different approaches were used to quantify potential surface effects from deep sublevel cave mining in the Kiirunavaara Mine. The first approach was applied to Sjömalmen involving three-dimensional (3D) numerical modelling, utilising the so-called 'caving algorithm' developed by Itasca, for future mining down to Level $1365 \mathrm{~m}$. The methodology used, and the results obtained, are further described in Section 2. The second approach was used for the main orebody and involved 2D modelling using a caving simulation scheme initially developed at the Luleå University of Technology. Simulations were run for very deep cave mining, down to Level $1800 \mathrm{~m}$, further described in Section 3. Both approaches comprised continuum modelling, in which caving was simulated implicitly. Explicit simulation of caving in discontinuum (particle flow) models is currently not feasible on a mine-scale, and the chosen approaches are judged to represent the macroscopical behaviour due to caving in a realistic manner.

Common to both approaches was that the extensive existing data on cave development and surface cratering (from observations) and ground surface deformations (from measurements) could be utilised for calibration of the numerical models. For the 3D modelling of Sjömalmen, surface cave cratering observations were used to calibrate the model for historic mining. For the $2 \mathrm{D}$ modelling of the main orebody, calibration was done using observations of surface cracking and locations of the limits of the environmental strain criterion (derived from GPS measurements).

\section{Cave modelling of Sjömalmen}

\subsection{The Itasca caving algorithm}

The caving algorithm as implemented in FLAC3D (Itasca 2013) attempts to predict the limits of the five geomechanical zones associated with caving in the conceptual model by Duplancic and Brady (1999): (i) elastic zone, (ii) seismogenic zone, (iii) yielded zone, (iv) air gap, and (v) mobilised zone. The numerical approach was developed successively over the past 15 years as part of the industry-funded International 
Caving Study (ICS) and the Mass Mining Technology (MMT) projects, and has been used successfully at a number of existing and planned caving projects, for example see Sainsbury et al. (2010, 2011a, 2011b).

The caving and stress-redistribution processes inherently involves large deformations, shear along pre-existing joints and bedding surfaces, fracturing of intact rock blocks and fragmentation of the rock mass. Ideally, one would model this process using a discontinuum approach. However, the computational size and time requirements to solve mine-scale problems make it currently impossible to tackle the problem completely with the discontinuum approach. Instead, an algorithm to simulate caving has been developed within the concept of a continuum-based model. The constitutive rock mass response required to represent caving (i.e. rock mass yield, weakening, dilation and bulking) was developed using strain-softening constitutive models, with strain-dependent properties adjusted to reflect the impacts of dilation and bulking that accompany caving. The implemented caving algorithm enables the following:

- Development of a large, 3D mine layout and progressive advance of undercutting and draw.

- Production-driven progression of the yielded zone up from the undercut and production areas, and the associated loss of cohesion and tensile strength associated with the rock mass failure.

- Simulation of continuous upward advance of the yielded zone when a sufficient hydraulic radius of the undercut has been achieved.

- Stalling of the yield zone and associated air-gap development prior to achieving critical hydraulic radius or when the cave advances through more competent ground.

- Mobilisation of yielded ground, and associated dilation and bulking with continued draw.

- Modulus softening as a function of bulking and associated redistribution of stress to abutments and pillars resulting from cave propagation.

- Dilation shut-off at the bulking limit.

- Simulation of cave impact on surface subsidence.

- Prediction of seismogenic zones accompanying the cave propagation.

Within the caving model, a rigorous mass-balance routine is implemented to ensure that the tonnes-based production schedule is represented accurately within the numerical model. Although the routine is computationally intensive, and can lead to relatively long model run times (of the order of weeks), the numerical approach is deemed necessary to capture accurately the mechanisms of damage, yield, dilation and bulking necessary to correctly reproduce the evolving cave shape and propagation rates in response to a step-wise production schedule. 3D isosurfaces are output graphically to outline the limits of yield and movement zones, which are defined within the context of the conceptual model for caving.

Due to the large displacements involved in caving, mesh deformation becomes extreme in large-strain mode. While it may be possible to employ dynamic remeshing techniques to accommodate this, a simpler approach in which caving is simulated in small-strain mode is adopted. It is important, however, that mass balance is maintained; thus, node coordinates are not updated in small-strain mode but the zone density is adjusted continuously to reflect the volumetric changes that accompany bulking.

Draw simulation is an essential part of the caving algorithm. Production marches forward in time increments within the model from the start of the input schedule. To simulate draw, a layer of zones encompassing all active draw points for the current year are deleted within the model. Forces are then applied to grid points on the floor of the deleted volume to represent the resistance provided by the extraction level, while the grid points on the roof of the deleted volume have a small downward velocity applied to them that is proportional to the relative draw rate for the nearest draw point. The largest pull velocity (i.e. for the draw points with the highest production rate) is set low enough to ensure pseudo-static equilibrium throughout the model (to allow natural gravitational flow of the material and to avoid dynamic 'pulling' of the overlying material). The density of zones within the cave is updated constantly (based on the 
emergent volumetric strain) to maintain mass balance. The mass of material 'drawn' is calculated by monitoring the vertical displacement of zones located directly above the extraction level. Once the vertical displacement of a zone is greater than the distance between this zone and the extraction level, it is considered as having been extracted. The model is cycled until the mass produced from the numerical cave is consistent with what is to be produced from the actual cave for the current time increment (as defined by the draw schedule).

As the mass is drawn from the model, displacement and yielding can occur in the overlying zones (dictated by the stress state and yield strength of the rock mass, see also Section 2.2), and the cave may progress upward. The process is repeated for the remaining years in the schedule. As old draw points cease production, the undercut zones are converted to a cohesionless caved-rock material, allowing stresses to redistribute back into exhausted areas of the cave.

\subsection{The CaveHoek constitutive model}

The caving algorithm makes use of the strain-softening CaveHoek constitutive model in FLAC3D, developed specifically for the caving algorithm, and which allows for representation of modulus softening, density adjustment, dilation, dilation shutoff, scaling of properties to zone size, cohesion weakening, tension weakening and frictional strengthening (Pierce 2013). The CaveHoek model is based on the Hoek-Brown failure criterion (Hoek et al. 2002), in which the peak strength is estimated via the Geological Strength Index (GSI) as follows:

$$
\begin{gathered}
\sigma_{1}=\sigma_{3}+U C S\left(m_{b} \frac{\sigma_{3}}{U C S}+s\right)^{a} \\
m_{b}=m_{i} \exp \left(\frac{G S I-100}{28}\right) \\
s=\exp \left(\frac{G S I-100}{9}\right) \\
a=\frac{1}{2}+\frac{1}{6}\left(e^{-G S I / 15}-e^{-20 / 3}\right)
\end{gathered}
$$

where:

$$
\begin{aligned}
& \sigma_{1}=\text { major principal stress. } \\
& \sigma_{3}=\text { minor principal stress. } \\
& U C S=\text { uniaxial compressive strength of intact rock. } \\
& m_{b}=\text { Hoek-Brown parameter for the rock mass. } \\
& s \quad=\text { Hoek-Brown parameter for the rock mass. } \\
& a \quad=\text { Hoek-Brown parameter for the rock mass. } \\
& m_{i} \quad=\text { Hoek-Brown parameter for intact rock. } \\
& G S I=\text { Geological Strength Index. }
\end{aligned}
$$

In the model, plastic shear strain is commonly used as a scale for damage accumulated during yield under compression and can be used to control the rate at which the rock mass strength degrades from peak to residual. The plastic shear strain required to go from peak to residual strength is referred to as the critical strain, and is effectively a brittleness parameter. This brittleness impacts both the caveability of a given unit, as well as the rate at which a cave will propagate in height for a given amount of draw.

It is conceivable that a higher-quality rock mass (with higher GSI) with larger solid rock volume participating in the failure process, often will act in a more brittle manner, i.e., having a lower critical strain value. Conversely, a lower-quality rock mass (lower $G S I$ ) with higher fracture frequency often will act in a more 
ductile fashion, and thus exhibit a larger critical strain. An estimate of the relation between the critical strain, GSI and zone size $(d)$ was determined by a back-analysis of rock mass failure in caves and other openings (Lorig 2000).

$$
\text { critical strain }=(12.5-0.125 \times G S I) /(100 \times d)
$$

The presence of zone size within this relation recognises that the critical strain parameter is zone-size dependent in continuum models where shearing develops in bands that collapse to the minimum zone resolution, usually one zone width. In general, the above relation is not restricted to finite difference models (such as FLAC), although we have not conducted any tests with other numerical methods.

The residual strength is set through parameters $a_{\text {residual, }} m_{b \text {,residual }}$ and $s_{\text {residual, }}$ which typically are chosen to correspond to that of a bulked rock fill comprised of angular fragments (i.e. zero cohesion and a friction angle of $\left.40-45^{\circ}\right)$. Frictional strengthening is presumed to occur at the same rate as cohesion weakening. This means that the post-peak friction and cohesion is reached at the same strain value. Tension weakening can occur via two different mechanisms. The growth of new fractures during shear yield is expected to result in tension weakening, thus, the tensile strength of every zone is scaled with cohesion (based on the pre-mining ratio between cohesive and tensile strength). Any time a zone reaches its peak tensile strength, however, it is presumed to weaken permanently to zero tensile strength in a perfectly brittle fashion (i.e. it is no longer scaled with cohesion).

During caving, the rock mass will increase in volume (or bulk) due to dilation under shear, or due to volumetric expansion under tension. Thus, it is important to allow for dilatancy and irreversible volumetric expansion within the numerical model. While dilation angle is set as a standard material property, a dilation 'shutoff' is also applied to prevent zones from expanding to unrealistic levels during shear. Thus, the dilation is set to zero when a user-defined maximum bulking factor is reached. The bulking factor, $B$, or volumetric strain increment (VSI) is defined by:

$$
B=\frac{\Delta V}{V_{i}}=\frac{n}{1-n}
$$

where:

$$
\begin{aligned}
& \Delta V=\text { change in volume (positive }=\text { expansion) } . \\
& V_{i} \quad=\text { initial volume. } \\
& n \quad=\text { porosity. }
\end{aligned}
$$

The initial bulking factor is normally set to zero for an undisturbed and unbulked rock. A maximum bulking factor is specified by the user as input data to the model. The maximum porosity of angular rock fill is typically in the range of 40 to 50\%, which is equivalent to a bulking factor of 66 to 100\% (Pierce 2010).

The intact Young's modulus $\left(E_{i}\right)$ is used to calculate the rock mass Young's modulus $\left(E_{r m}\right)$, using the Hoek and Diederichs (2006) equation, which governs the rock mass elastic behaviour:

$$
E_{r m}=E_{i}\left(0.02+\frac{1}{1+e^{((60-G S I) / 11)}}\right)
$$

As a rock mass yields and then bulks via shear or tension under draw, it is expected to experience a significant drop in modulus. Representation of this drop is required in order to account for stress shedding away from the mobilised zone and into the surrounding rock mass. In addition, it is necessary to allow for modulus hardening that can occur when stresses are shed back onto exhausted or undrawn parts of the cave. Laboratory testing has shown that the modulus of a fragmented rock drops in a non-linear fashion with increased bulking, and that the rate of modulus change is a function of fragment shape and intact strength (Pappas \& Mark 1993). The relations from this test work has been extrapolated and embedded within the caving algorithm to update the modulus continuously for each zone based on the user-defined UCS, $B$ (bulking factor) and thickness-to-width ratio of the fragments (Pierce 2013). 


\subsection{Model geometry and set-up}

A numerical model of the Kiirunavaara orebody, together with the surrounding footwall and hangingwall host rock, was set up. The model was constructed as several boxes with the highest level of detail within the orebody and the box covering the adjacent part of the footwall and hangingwall. Decreasing zone density was applied for each box moving farther away from the area of highest interest, as illustrated in Figure 4. The total model size is $20,480 \times 20,480 \mathrm{~m}$ in horizontal direction, and 2,560 $\mathrm{m}$ in depth. Initial stress conditions were taken from Sandström (2003) and roller boundaries were applied to the vertical and bottom boundaries of the model, while the ground surface was simulated as a free surface. The production within the mine was divided into four categories depending on the degree of knowledge and documentation: (i) estimated historical mining, (ii) documented historical mining, (iii) planned future mining, and (iv) estimated future mining (illustrated in Figure 5).

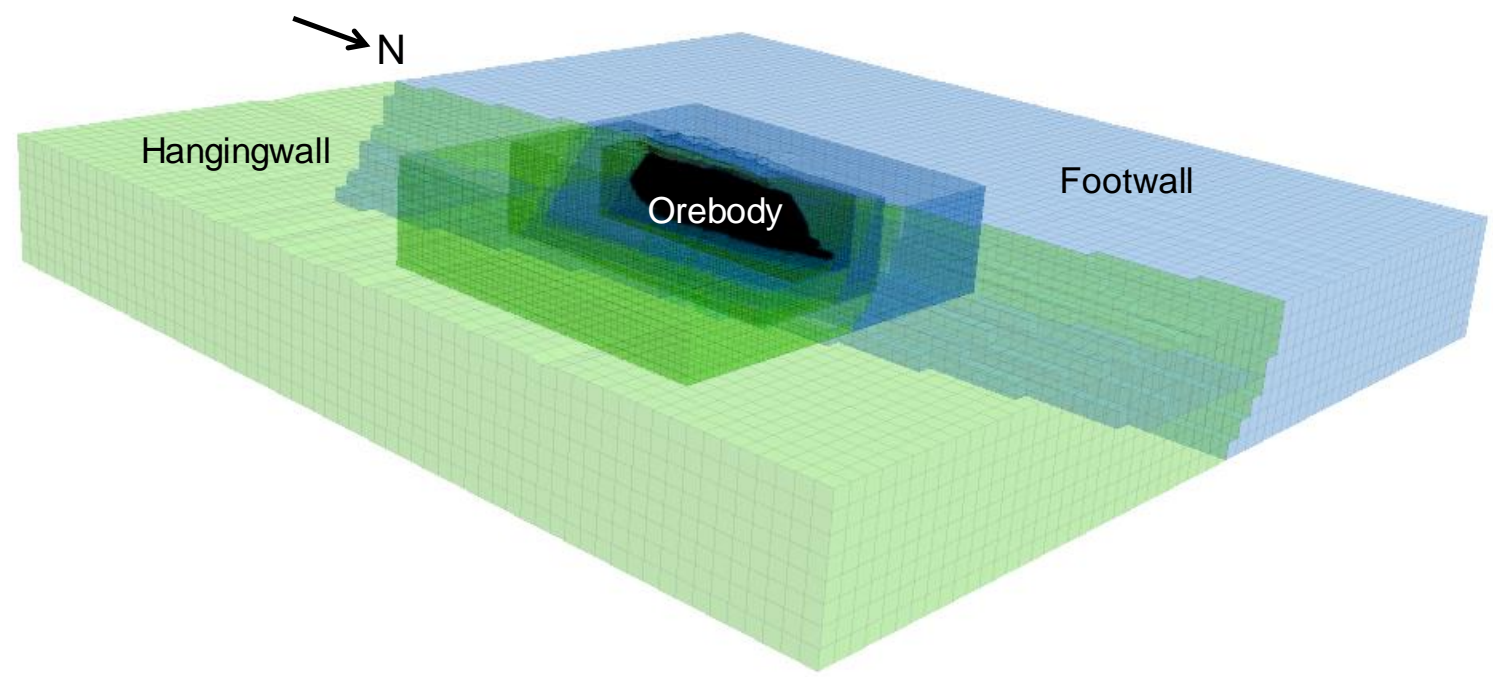

Figure 4 3D numerical model of the Kiirunavaara orebody and host rock, illustrating regions within the model with different zone density

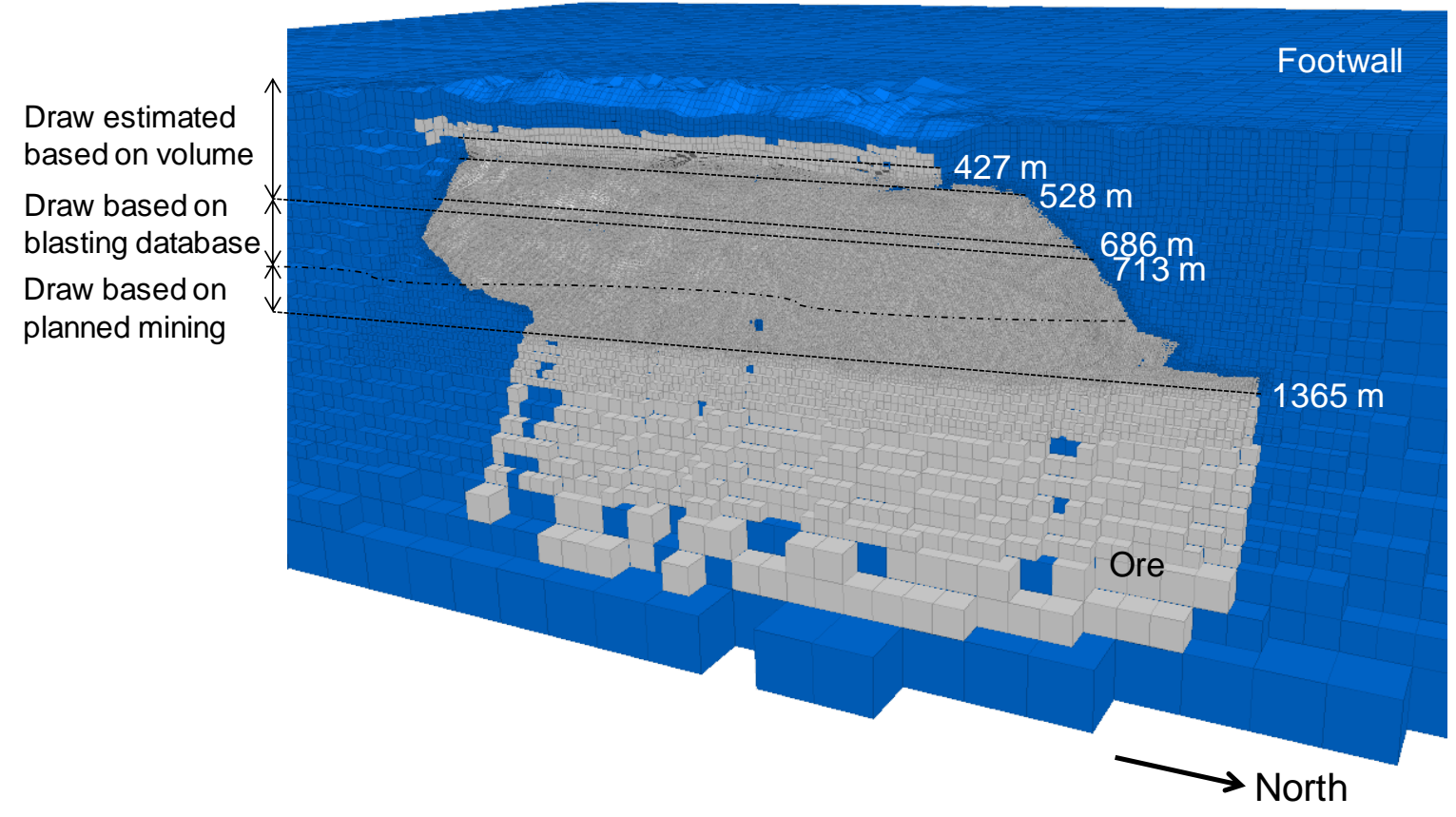

Figure 5 Perspective view of FLAC3D model, looking toward the footwall, showing orebody and mining levels, and draw schedule sources 


\subsection{Model calibration}

Rock mass properties were estimated based on previous analyses, existing characterisation data, and experience. A total number of 12 cases were analysed, in which the material properties for the orebody and footwall were kept constant, while three parameters were varied for the hangingwall rock mass (GSI, $E_{r m}$, and $\left.\sigma_{c i}\right)$, see Table 1. These three parameters were found to be those that influenced the behaviour most significantly. Initial parameter estimates were taken from Sainsbury and Stöckel (2012) and calibration was conducted by comparing modelling results with observed surface cratering above the Sjömalmen orebody. In the model, cratering is taken to correspond to vertical displacements of $1 \mathrm{~m}$ or more (downward), see Sainsbury (2012). The calibration was conducted for mining up until 2014.

Table 1 Material properties for the orebody, footwall and hangingwall rock mass in the 3D model for Sjömalmen using the CaveHoek constitutive model. Values marked as bold were those that provided the best match against observed behaviour

\begin{tabular}{|c|c|c|c|}
\hline Parameter & Orebody & Footwall & Hangingwall \\
\hline GSI & 58 & 58 & $58,63,68,70,73,75,78,80,90$ \\
\hline$\sigma_{c i}[\mathrm{MPa}]$ & 130 & 130 & 104,130 \\
\hline$m_{i}$ & 15 & 20 & 15 \\
\hline$E_{r m}[\mathrm{GPa}]$ & 15.8 & 15.8 & $8.1,15.8$ \\
\hline$v_{r m}$ & 0.25 & 0.25 & 0.25 \\
\hline$\rho_{r m}\left[\mathrm{~kg} / \mathrm{m}^{3}\right]$ & 4,600 & 2,700 & 2,700 \\
\hline
\end{tabular}

$G S I=$ Geological Strength Index,; $\sigma_{c i}=$ uniaxial compressive strength of intact rock; $m_{i}=$ Hoek-Brown parameter for intact rock; $E_{r m}=$ Young's modulus for the rock mass; $v_{r m}=$ Poisson's ratio for the rock mass; $\rho_{r m}=$ density for the rock mass

Two sets of material properties gave particularly good agreement with observed cratering. The best agreement was found for the case with $\sigma_{c i}=104 \mathrm{MPa}, E_{r m}=8.1 \mathrm{GPa}$, and $G S I=58$ (see Table 1 ). The results compared very well with observed surface cratering in the hangingwall and also, to some extent, for the plunge hangingwall (in north direction). However, a case with higher GSI-value and higher intact rock strength gave a slightly better agreement with observed cratering in the north direction, but significantly underestimated the surface cratering on the hangingwall (east) side. An example of calculated cratering limits compared to actual observations is shown in Figure 6.

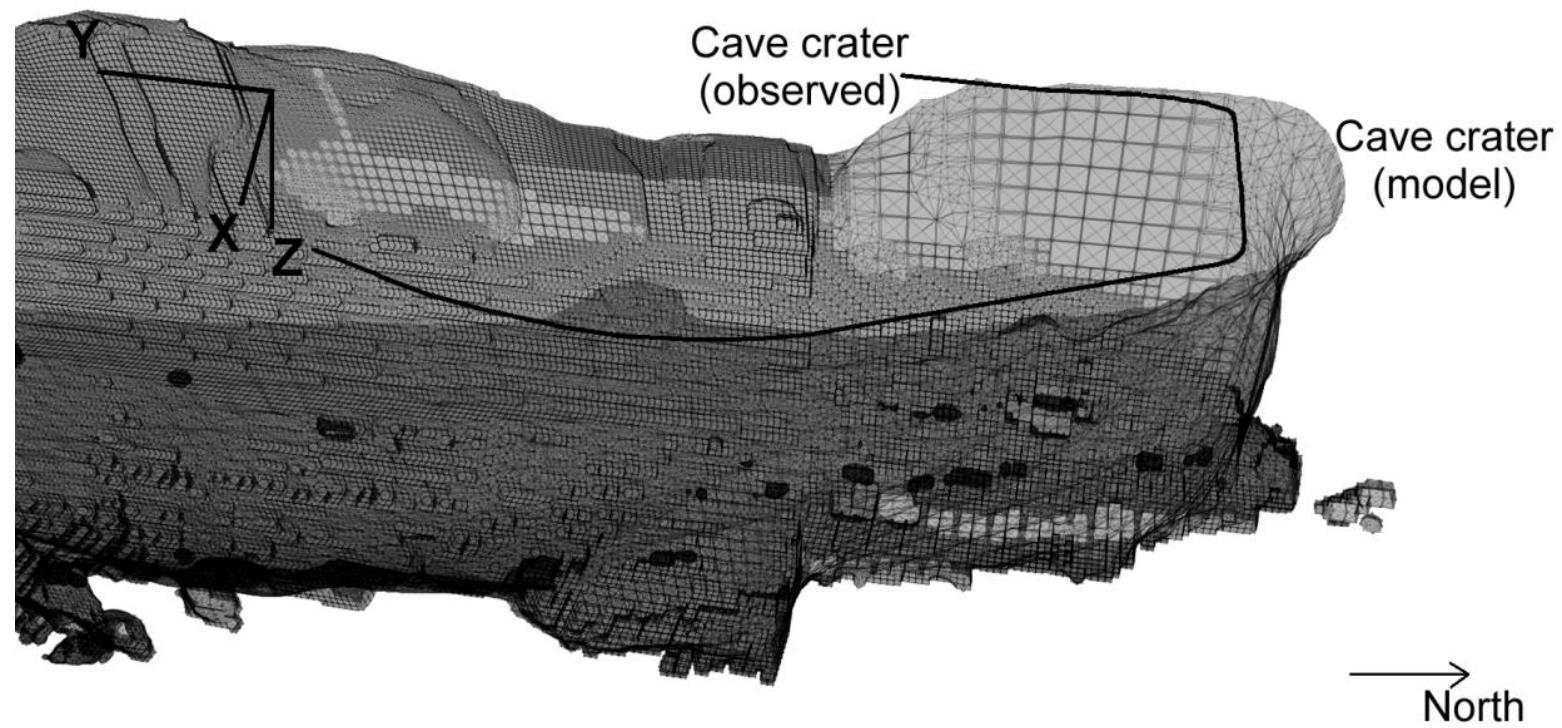

Figure 6 Perspective view showing surface cratering in the numerical model compared to observed limits of surface cratering for year 2014 
Following the calibration, the model results were also compared with data from deformation measurements using GPS, more specifically the derived location of the environmental criterion limit on the ground surface. This comparison served as a validation of the model calibration, in that results were compared to a different data set. The validation showed generally good agreement between model results and measurement data, however, with the model being slightly conservative (i.e. predicting slightly higher differential deformations on the ground surface).

\subsection{Calculations for future mining}

Prediction of future ground surface deformations from mining of Sjömalmen was obtained by running the model for mining down to Level $1365 \mathrm{~m}$. The case with $\sigma_{c i}=104 \mathrm{MPa}, E_{r m}=8.1 \mathrm{GPa}$, and $\mathrm{GSI}=58$ was primarily used for the calculations for continued mining, with some sensitivity analysis using slightly higher strength values for the rock mass also included. The model results were evaluated in terms of the location of the environmental criterion limit on the ground surface. It was found that the extent of the zone of mining-induced deformations on the ground surface increased significantly with future mining at depth. An example is presented in Figure 7, showing both the cave crater limit and the environmental criterion limit.
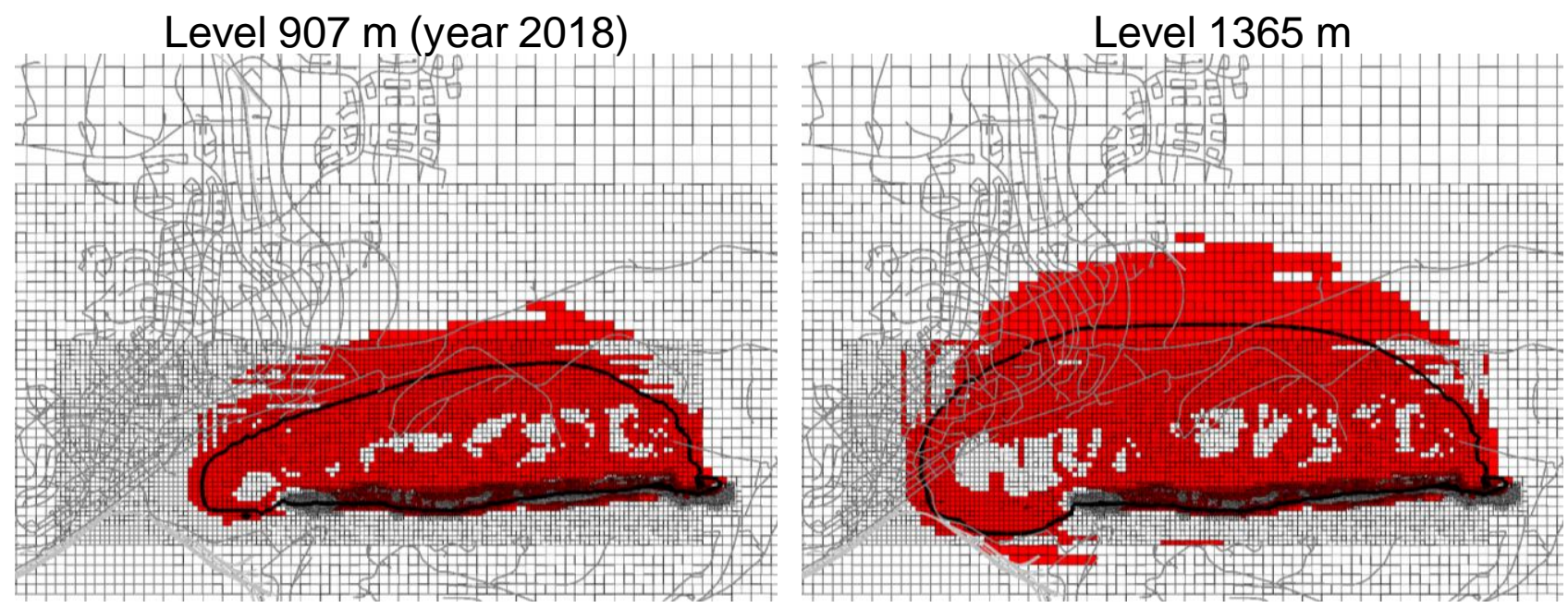

Figure 7 Area on the ground surface for which the environmental deformation criterion has been exceeded (red colour) for mining to Level $907 \mathrm{~m}$ (left) and Level $1365 \mathrm{~m}$ (right) in Sjömalmen. The indicated limit of surface cratering in the model is marked with a thick black line

The limit angles for the environmental criterion, defined as the angle between the horizontal plane and a line from the active mining level to the location of the environmental criterion limit on the ground surface, were also calculated. The calculated limit angles are more-or-less constant with mining at depth, implying that the empirical limit angles currently used for prognoses may also be applicable in the future. However, for the northern tip of the orebody, the numerical model results indicate a steeper limit angle than that currently used in the empirical prognosis methodology. Thus, the extent of surface cratering and mining-induced deformations may be less above Sjömalmen in the north direction, than previously predicted. Additional work may be required to verify this finding before implementation in future prognoses.

\section{Cave modelling of deep mining in Kiirunavaara}

\subsection{Caving simulation and model set-up}

The 3D calculations, presented previously, are fairly time-consuming. To provide faster calculations, a simpler 2D approach was adopted for analysing the surface effects of deep sublevel cave mining. This approach builds on the work by Villegas Barba and Nordlund (2013), in which the hangingwall was split into 'mining blocks' of $50 \mathrm{~m}$ height and $28 \mathrm{~m}$ width. Cave mining was simulated by first mining the block in the orebody closest to the hangingwall. This is followed by extracting the next block in the orebody (toward the 
footwall), while replacing the previously mined block with caved rock material at the same time as the next block in the hangingwall is mined to simulate the air gap developing. This air gap, and the mined block in the orebody is then 'backfilled' with caved rock material, and a new air gap is extracted vertically above the hangingwall block, as shown in Figure 8. This process is then repeated until the desired mining depth is reached. This approach is much simpler compared to the 3D modelling previously described, and the possible implications, thereof, were assessed as part of this study.

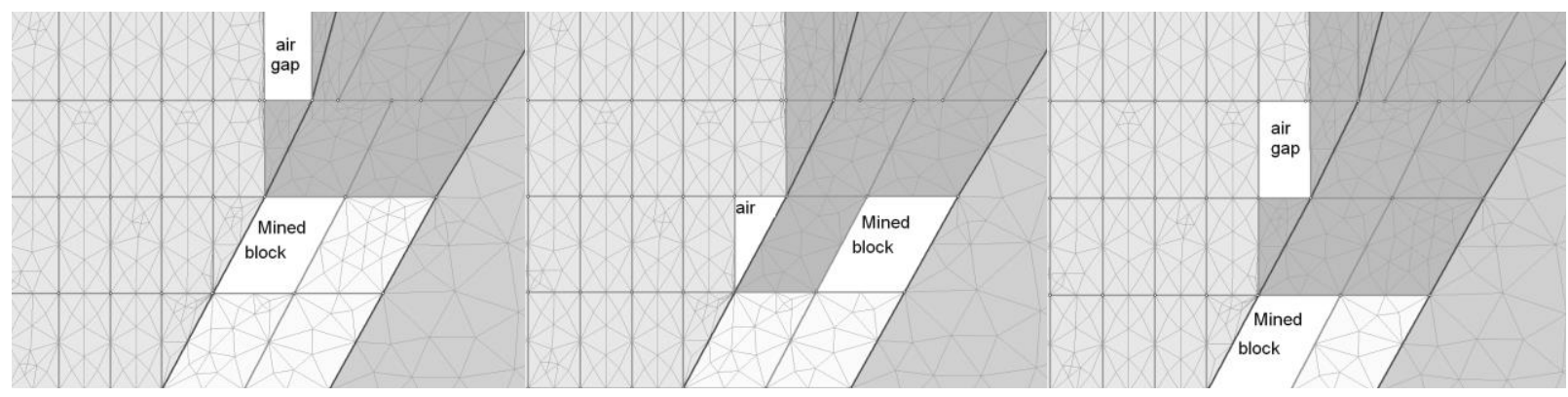

Figure 8 Simulation of sublevel cave mining (from Villegas Barba \& Nordlund 2013)

In this study, the methodology by Villegas Barba and Nordlund (2013) was implemented in the 2D finite difference code FLAC (Itasca 2016a). The model was set up for the Y2600 vertical cross-section of the mine, located in the mid portion of the main orebody. This section was judged fairly representative of the mining geometry for the main orebody and for which 2D conditions could reasonably be assumed. Moreover, ore width (approximately $100 \mathrm{~m}$ ) and ore dip (approximately $60^{\circ}$ ) were both fairly constant within this cross-section. The orebody limits were extrapolated below the currently known mineralisation down to Level $1800 \mathrm{~m}$. The total model size was $9,000 \times 3,500 \mathrm{~m}$, with an element size of $7 \times 7 \mathrm{~m}$ in a region around the orebody, gradually increasing to $14 \times 14 \mathrm{~m}$ at the model boundary (see Figure 9).

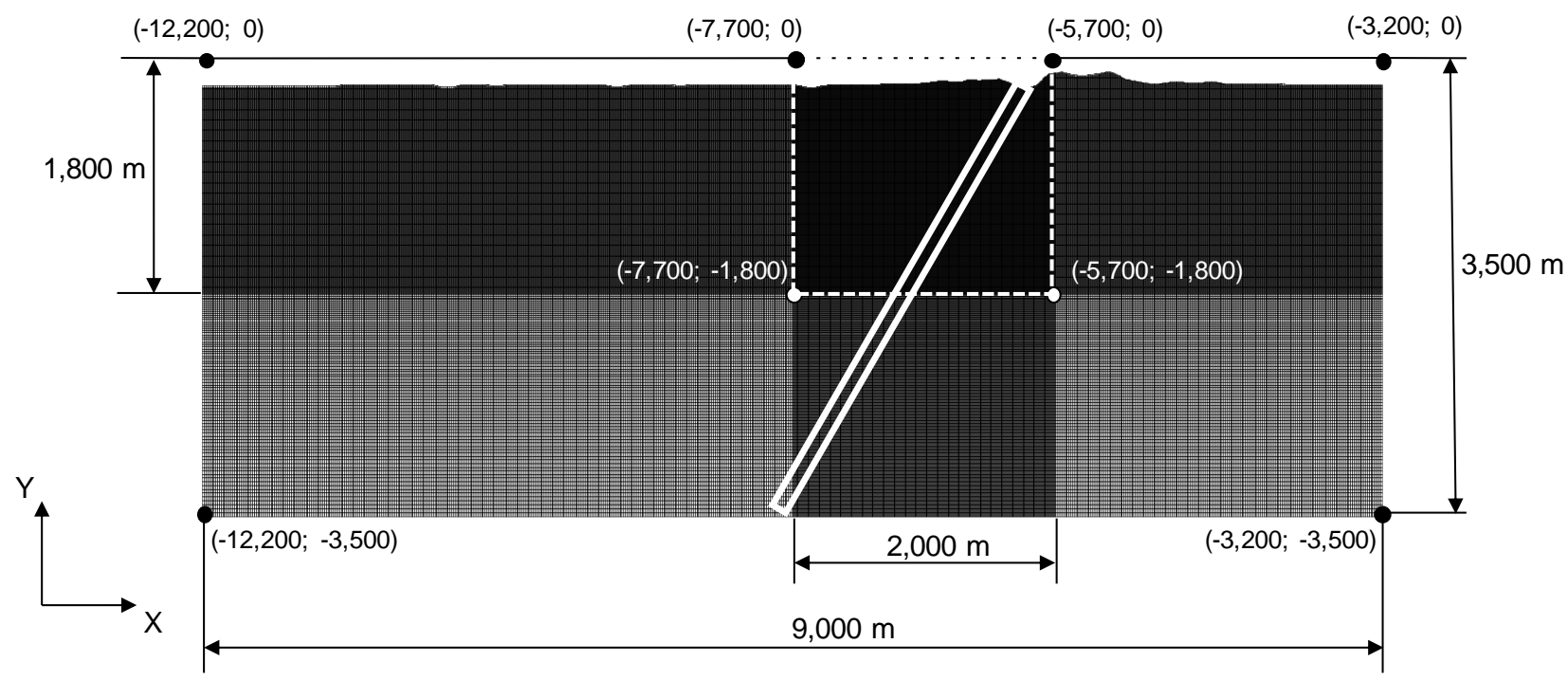

Figure 9 Model geometry in FLAC with the approximate position of the orebody in white

The orebody and the hangingwall rock mass was split into mining blocks of $21 \mathrm{~m}$ width and $28 \mathrm{~m}$ height to simulate mining and caving as per the above. Three different mining and caving sequences were simulated: (i) Type 1 being similar to Villegas Barba and Nordlund (2013) shown in Figure 8, (ii) Type 2 with faster caving in which the air gap is twice as high $(2 \times 28 \mathrm{~m})$ in each step, and (iii) Type 3 with slower caving in which mining of the next sublevel does not commence until caving from the level above has reached the ground surface. Initial stresses and boundary conditions were taken to be the same as in the 3D model for Sjömalmen, previously described. All calculations were run in small-strain mode to prevent premature model collapse and allow simulations to large mining depths. 


\subsection{Model calibration}

The rock mass was simulated as a continuum material and the entire rock mass was given the same material properties for a given calculation case. This simplification was deemed acceptable since the focus of this work was to study hangingwall behaviour. Moreover, there is not enough detailed information available to justify assumptions on varying properties within the hangingwall, either laterally or with depth, although this is almost certainly the case in reality. Ideally, a constitutive model similar to the CaveHoek model previously described should be used, but this model has not (yet) been implemented for FLAC in 2D. Hence, several perfectly-plastic and strain-softening constitutive models were applied and tested as part of this study. The material properties were based on previous analyses, as follows:

- Set A: Perfectly-plastic Mohr-Coulomb material model using parameter values from Sjöberg et al. (2012).

- Set B: Parameter values from Villegas Barba and Nordlund (2013) with the following cases analysed:

- Sets B1, B2, B3: Strain-softening Mohr-Coulomb material with variations in strength parameters and elastic constants.

○ Set B4: Perfectly-plastic Hoek-Brown model.

- Set C: Perfectly-plastic Hoek-Brown model with parameter values from the 3D model of Sjömalmen, described previously in this paper.

The caved rock was simulated as a perfectly-plastic Mohr-Coulomb material with density of $2,000 \mathrm{~kg} / \mathrm{m}^{3}$, Young's modulus of $200 \mathrm{MPa}$, and friction angle of $35^{\circ}$ with no cohesion or tensile strength. A total of 15 cases with different combinations of material models and properties (Sets A, B, C), and mining and caving sequence (Types 1, 2, 3) were analysed.

The model was calibrated primarily by calculating the differential deformations (strains) developing on the ground surface and determining the location of the environmental deformation criterion used by LKAB $(0.3 \%$ horizontal strain and/or $0.2 \%$ tilt), and comparing this with the actual location inferred from conducted GPS deformation measurements in Kiruna. Differential deformations were calculated over a distance of $49 \mathrm{~m}$ (seven elements) and for all grid points along the ground surface in the model. Comparisons with observational data was primarily done for four points in time; years 2000, 2004, 2010, and 2014. The results showed reasonable agreement between the model and the observations in terms of the location of the environmental criterion limit on the ground surface. The constitutive models and properties of Sets $B$ and $C$ provided that best agreement. In particular two cases (5 and 10) with Set C-parameters and the Hoek-Brown constitutive model matched observations reasonably well, see Figure 10 and Table 2. Case 14 is not shown in this figure as this case deviated significantly from the other cases.

The model results also showed that the horizontal strain limit was always first exceeded (at a particular point), with the vertical strains (tilt) being significantly lower. This is also in agreement with observations and measurement data, implying that the rock mass initially behaves as a continuum under the influence of the high initial horizontal stresses in the area. However, a unique set of material properties could not be inferred from the calibration, as different sets of parameter values provided better agreement for some years and worse for others. The different mining and caving sequences simulated were less influential. 


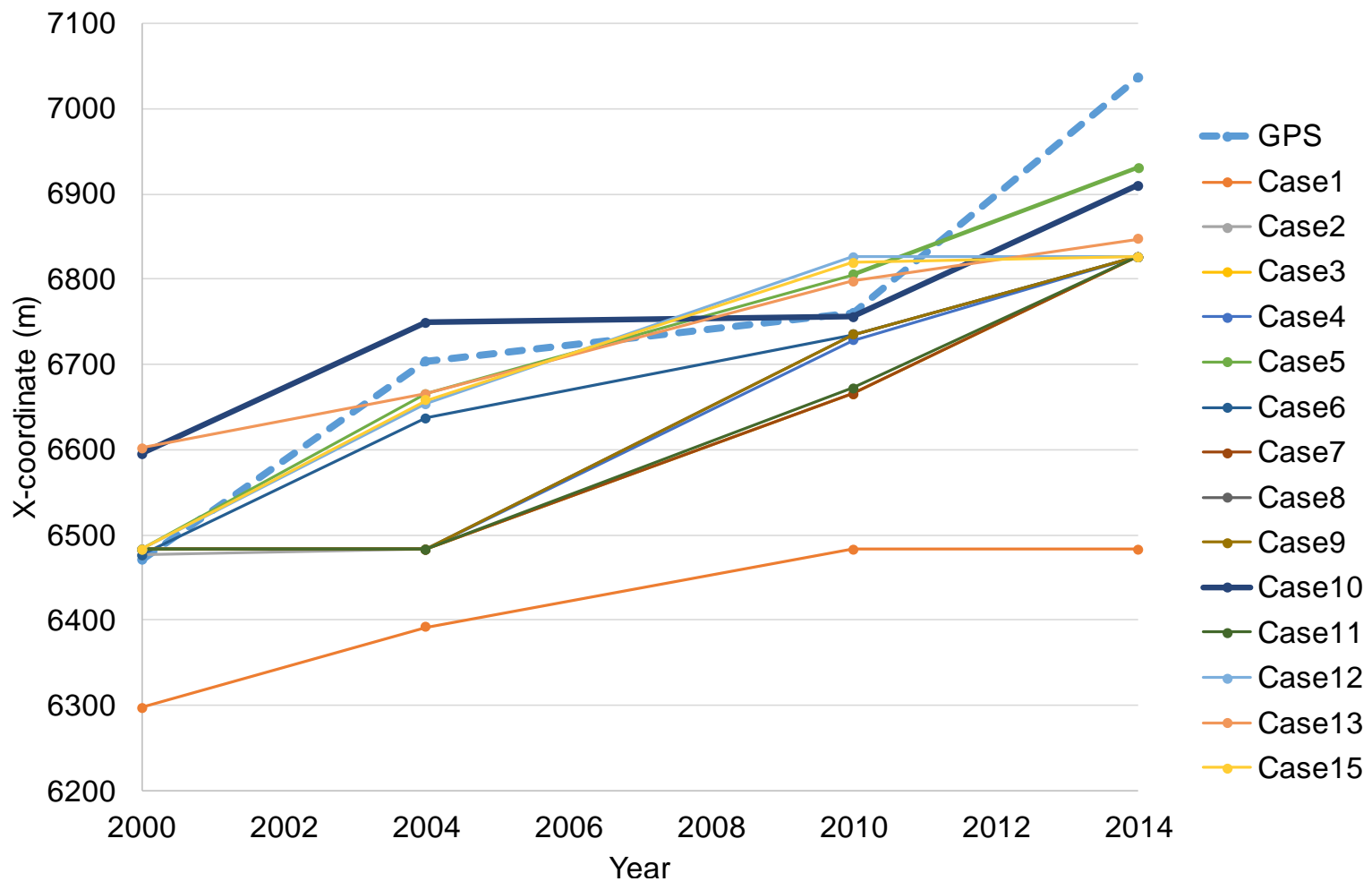

Figure $10 \mathrm{X}$-coordinate for the location of the environmental criterion from measurements (GPS) compared to results from modelling (Cases 1-15, except Case 14) for years 2000 to 2014

Table 2 Parameter values for the hangingwall rock mass for the cases that bounded model response

\begin{tabular}{lll}
\hline Parameter & Case $\mathbf{5}$ & Case $\mathbf{1 0}$ \\
\hline Constitutive model & Hoek-Brown, perfectly plastic & Hoek-Brown, perfectly plastic \\
\hline$G S I$ & 58 & 58 \\
\hline$\sigma_{c i}[\mathrm{MPa}]$ & 104 & 104 \\
$m_{i}$ & 15 & 15 \\
\hline$\rho_{r m}\left[\mathrm{~kg} / \mathrm{m}^{3}\right]$ & 2,700 & 2,700 \\
$v_{r m}$ & 0.22 & 0.22 \\
\hline$D$ & 0.0 & 0.5 \\
$E_{r m}[\mathrm{GPa}]$ & 8.1 & 8.1 \\
$\sigma_{t m}[\mathrm{MPa}]$ & 0.29 & 0.19 \\
\hline$\psi\left[{ }^{\circ}\right]$ & 10 & 10 \\
\hline$a$ & 0.503 & 0.503 \\
$m_{b}$ & 3.35 & 2.03 \\
$s$ & 0.0094 & 0.0037 \\
\hline
\end{tabular}

$G S I=$ Geological Strength Index; $\sigma_{c i}=$ uniaxial compressive strength of intact rock; $m_{i}=$ Hoek-Brown parameter for intact rock; $\rho_{r m}=$ density for the rock mass; $v_{r m}=$ Poisson's ratio for the rock mass; $D=$ disturbance factor in the Hoek-Brown failure criterion; $E_{r m}=$ Young's modulus for the rock mass; $\sigma_{t m}=$ tensile strength for the rock mass; $\psi=$ dilation angle, $a=$ Hoek-Brown parameter for the rock mass; $m_{b}=$ Hoek-Brown parameter for the rock mass; $s=$ Hoek-Brown parameter for the rock mass 


\subsection{Calculations for future mining}

With none of the analysed cases providing a perfect match with observations, and considering the uncertainties in the geomechanical data and the simplifications made, a number of cases were selected for analysis of future mining. A total of eight cases were run, using constitutive models and properties according to Sets $B$ and $C$ and with the Type 1 mining and caving sequence for all cases except one in which the Type 2-sequence was used.

Mining was simulated from the current deepest production level at approximately Level $1100 \mathrm{~m}$ down to Level $1800 \mathrm{~m}$. The results were only evaluated with respect to the location of the environmental criterion limit on the ground surface. Interestingly, the calculations showed similar locations of the environmental criterion limit for virtually all cases. The results were, thus, not particularly sensitive to small variations in geomechanical characteristics. Cases 5 and 10 (Table 2), practically bounded the model response, and the resulting limit angles for the location of the location of the environmental criterion are shown in Table 3.

Table 3 Calculated limit angles for the environmental strain limit (for horizontal strains) for simulated future mining at depth in Kiirunavaara

\begin{tabular}{lllll}
\hline Model case (cf. Table 2) & Level $1200 \mathrm{~m}$ & Level $1400 \mathrm{~m}$ & Level $1600 \mathrm{~m}$ & Level $1800 \mathrm{~m}$ \\
\hline Case 5 & $55^{\circ}$ & $47^{\circ}$ & $31^{\circ}$ & $36^{\circ}$ \\
Case 10 & $43^{\circ}$ & $46^{\circ}$ & $40^{\circ}$ & $37^{\circ}$ \\
\hline
\end{tabular}

It is clear that deeper mining will result in more extensive effects on the ground surface, possibly with the exception of the deepest mining level, which shows the same predicted location of the environmental criterion limit as the level above. The limit angles for the environmental criterion range from $43^{\circ}$ for mining at Level $1200 \mathrm{~m}$, to $31^{\circ}$ for mining at Level $1600 \mathrm{~m}$, confirming that the extent of mining-induced ground deformations may actually increase with mining depth. These values on the limit angles are also lower than the value currently used for prognosis (Stöckel et al. 2013).

\section{Discussion}

Increasing mining depths are often associated with an increase in rock stresses, development of mining-induced seismicity, higher demands on rock reinforcement, and generally more difficult mining conditions at production levels and around mining stopes. In this paper, we have shed light on a different rock mechanical issue, namely the possible surface effects from deep cave mining. Although perhaps less common, the consequences of mining-induced ground disturbances may be significant, especially in cases with mining or civil infrastructure located on the ground surface in the vicinity of a mining area. The purpose of the present study was to study the surface effects from deep sublevel cave mining of the Kiirunavaara orebody, and to test different numerical approaches to simulate caving and ground deformation behaviour. Moreover, it was also hoped that this would provide data on how well (or poor) the currently used empirical prediction methodology (using limit angles) would work for deeper mining.

Both the numerical modelling approaches used in this study showed that mining-induced ground deformations should be also expected when conducting sublevel cave mining at large depths in the Kiirunavaara Mine. The 3D approach, in which material strain-softening, bulking and dilation, and mass balance are all considered, revealed that caving and surface influences will continue more-or-less in the same fashion when mining continues for another 300-400 $\mathrm{m}$ towards depth. Thus, there appears to be no, or at least very little, effects from increased confinement and bulking with deeper mining.

The 2D model predicted a relative increase in the volumes affected by cave mining, as extraction progressed towards even larger depths. However, material bulking is not explicitly accounted for in this simplified approach, and the results may thus be overly conservative. Moreover, strain-softening material models were only partly used while it is generally agreed that a caving rock mass experience significant softening behaviour. The possible influence from this are not known. It may be beneficial to further explore 
the 3D caving algorithm and apply this for deep to ultra-deep mining to confirm (or discard) the findings from the more simplified 2D caving simulation. The recently developed 'Bonded Block Model' in 3DEC (Itasca 2016b) may also be an alternative worth exploring for simulating caving.

Another uncertainty pertains to the material properties of the rock mass. This study showed that the caving progression and the associated ground deformations were sensitive to the choice of material properties. This fact certainly facilitated calibration but, on the other hand, it also implies that fairly detailed knowledge of the geomechanical characteristics are important. This is a daunting task for the problem at hand, involving very large volumes of rock. Nevertheless, even small steps toward an improved characterisation of the rock mass, in particular in the cap rock and the hangingwall, are valuable and efforts need to be devoted for pursuing this task.

It may also be speculated that material properties change with depth due to increased confinement and less influence of (geological) surface weathering etc. While hard data on this may be difficult to obtain, both of these numerical modelling approaches may be used to study how sensitive the results are to changes in strength and stiffness with depth. In fact, the numerical models may also be used to test the sensitivity of changes and/or variations in material properties in the cap rock and near-surface hangingwall rocks, to further our understanding. Moreover, such sensitivity studies may help to target characterisation and investigations of the rock mass.

Finally, the presence of large-scale geological structures may influence the caving behaviour, as shown by e.g. Sainsbury (2012). A preliminary structural model exists for the Kiirunavaara Mine, but with most structures not being validated. However, this may still be used as a starting point for discontinuum analyses, to increase the understanding of their potential influence.

\section{Conclusion}

The following general conclusions may be drawn:

- Deeper sublevel cave mining in the Kiirunavaara Mine will likely lead to continued caving and ground deformations to, at least, the same extent as experienced so far. None of the modelling approaches applied indicated any arrest or decrease in mining-induced deformations due to, for instance, increased confinement with depth.

- Calibration against observations (surface cratering, measured differential deformations) proved invaluable for increasing the reliability in the models later used for prediction purposes. Some fine-tuning may be required, e.g. adjusting the threshold value used for cratering in the model.

- Both modelling approaches have distinct pros and cons. The 2D approach, in addition to obviously being limited to where 2D geometrical conditions can be reasonably assumed, may also be too simplistic with regards to caving simulation and material models used. There is thus a potential that some important mechanisms are not captured. The 3D modelling approach is more comprehensive but, on the other hand, also more time-consuming.

The following specific conclusions with respect to the prognosis work at LKAB as well as future modelling improvements may also be stated:

- The currently used values on limit angles in the empirical prognosis methodology appear reasonable, at least for continued mining to Level $1365 \mathrm{~m}$. For the northern tip of the orebody, steeper angles may even be applicable.

- For deeper mining, the reliability in limit angles may be questioned, as they appear to be non-conservative. These findings need to be further verified, e.g. through additional modelling, preferably using the 3D caving algorithm. It should also be considered to apply the CaveHoek constitutive model in a 2D numerical model. 
- An improved characterisation of the rock mass in the cap rock and hangingwall is important for increased reliability in predictive analyses. Models may be used as a tool for directing investigations by conducting sensitivity analysis of selected scenarios.

- The possible influence of large-scale structures should be investigated by including these in a numerical model. It is likely that assumptions regarding the extent and characteristics of such structures must be made, but the model results will still be valuable in increasing our understanding and help to define required investigations.

\section{Acknowledgement}

The work presented in this paper was fully funded by LKAB, and the approval to publish and present the work is greatly appreciated. We are also grateful for the permission to use the caving algorithm, as well as the training and technical support provided by Matt Pierce of Itasca Consulting Group, Inc. Thanks are also due to Carlos Quinteiro and Jimmy Töyrä with LKAB, for paper review.

\section{References}

Duplancic, P \& Brady, BHG 1999, 'Characterisation of caving mechanisms by analysis of seismicity and rock stress', in G Vouille \& P Bérest (eds), Proceedings of the 9th ISRM Congress on Rock Mechanics, vol. 2, Balkema, Rotterdam, pp. 1149-1053.

Hoek, E, Carranza-Torres, C \& Corkum, B 2002, 'Hoek-Brown Failure Criterion - 2002 Edition', in R Hammah (ed.), Proceedings NARMS-TAC 2002: Mining and Tunnelling Innovation and Opportunity, vol. 1, University of Toronto Press, pp. 267-273.

Hoek, E \& Diederichs, MS 2006, 'Empirical estimation of rock mass modulus', International Journal of Rock Mechanics and Mining Sciences, vol. 43, pp. 203-215.

Itasca 2013, FLAC3D, software, version 5.01, Itasca Consulting Group, Inc., Minneapolis.

Itasca 2016a, FLAC, software, version 8.0, Itasca Consulting Group, Inc., Minneapolis.

Itasca 2016b, 3DEC, software, version 5.2, Itasca Consulting Group, Inc., Minneapolis.

Lorig, L 2000, The Role of Numerical Modelling in Assessing Caveability, Itasca Consulting Group, Inc., report to the International Caving Study, ICG00-099-3-16.

Mäkitaavola, K, Stöckel, B-M, Sjöberg, J, Hobbs, S, Ekman, J, Henschel, M \& Wickramanayake, A 2016, 'Application of InSAR for Mmonitoring deformations at the Kiirunavaara Mine', Proceedings of the 3rd International Symposium on Mine Safety, Science and Engineering (ISMS 2016), McGill University, Montreal.

Pappas, DM \& Mark, C 1993, Behavior of simulated longwall gob material, report of investigations 9458 USBM.

Pierce, M 2010, A Model for Gravity Flow of Fragmented Rock in Block Caving Mines, PhD thesis, University of Queensland.

Pierce, M 2013, 'Numerical modeling of rock mass weakening, bulking and softening associated with cave mining', ARMA e-Newsletter Spring 2013, no. 9, www.armarocks.org

Sainsbury, BL 2012, A model for cave propagation and subsidence assessment in jointed rock masses, PhD thesis, The University of New South Wales, Kensington, New South Wales.

Sainsbury, DP, Sainsbury, B \& Lorig, LJ 2010, 'Investigation of caving induced subsidence at the abandoned Grace Mine', in Y Potvin (ed.), Proceedings of the Second International Symposium on Block and Sublevel Caving, Australian Centre for Geomechanics, Perth, Western Australia, pp. 189-204.

Sainsbury, BL, Sainsbury, DP \& Pierce, ME 2011a, 'A historical review of the development of numerical cave propagation simulations', in DP Sainsbury, RD Hart, CJ Detournary \& MJ Nelson (eds), Proceedings of the 2nd International FLAC/DEM Symposium - Continuum and Distinct Element Numerical Modeling in Geomechanics, Itasca International Inc., Minneapolis, pp. 23-36.

Sainsbury, DP, Sainsbury, BL, Board, MP \& Lorig, LJ 2011b, 'Numerical back-analysis of structurally controlled cave initiation and propagation at the Henderson Mine', in AT Innacchione, GS Esterhuizen \& AN Tutuncu, Proceedings of the 45th US Rock Mechanics/Geomechanics Symposium, American Rock Mechanics Association, Alexandria, Virginia.

Sainsbury, BL \& Stöckel, B-M 2012, 'Historical assessment of caving induced subsidence at the Kiirunavaara Lake orebody', Proceedings of the 6th International Conference and Exhibition on Mass Mining, Canadian Institute of Mining, Metallurgy and Petroleum, Westmount, Quebec.

Sandström, D 2003, Analysis of the Virgin State of Stress at the Kiirunavaara Mine, Licentiate thesis, Luleå University of Technology, Luleå.

Sjöberg, J, Perman, F, Quinteiro, C, Malmgren, L, Dahnér-Lindkvist, C \& Boskovic, M 2012, 'Numerical analysis of alternative mining sequences to minimise the potential for fault slip rock bursting', Mining Technology, vol. 121, no. 4, pp. 226-235.

Stöckel, B-M, Mäkitaavola, K \& Sjöberg, J 2013, 'Hangingwall and footwall stability issues in sublevel caving', in P Dight (ed.), Proceedings of the 2013 International Symposium on Slope Stability in Open Pit Mining and Civil Engineering, Australian Centre for Geomechanics, Perth, Western Australia, pp. 1045-1060.

Villegas Barba, TF \& Nordlund, E 2013, 'Numerical analyses of the hangingwall failure due to sublevel caving: study case', International Journal of Mining and Mineral Engineering, vol. 4, no. 3, pp. 201-223. 